\title{
OS CAMINHOS DAS CRIMINOLOGIAS CRÍTICAS: UMA REVISÃO BIBLIOGRÁFICA
}

\author{
THE WAYS OF CRITICAL CRIMINOLOGY: A LITERATURE REVIEW
}

\author{
Carolina Costa Ferreira ${ }^{1}$
}

\section{RESUMO}

As Criminologias Críticas recebem, desde os anos 2000, uma séria crítica: não basta apenas o diagnóstico do não (ou do mau) funcionamento do sistema de justiça criminal: são necessárias respostas interventivas à crise do encarceramento em massa, do aumento da cultura punitiva e da crise de alteridade pela qual passa a sociedade. Diante deste desafio, o presente artigo apresenta a trajetória das Criminologias Críticas e seus diferentes caminhos, sob a forma de revisão bibliográfica, para que se inicie um novo caminho, a fim de propor o enfrentamento aos discursos punitivos, na academia e nas instâncias formais de controle.

Palavras-chave: Criminologias críticas; Sistema de Justiça Criminal; Realismo de Esquerda; Criminologia Latino-Americana; Criminologia Brasileira.

\begin{abstract}
Critical Criminology receive, from the 2000s, a serious criticism: not enough to diagnose not (or bad) functioning of the criminal justice system are needed interventional responses to mass incarceration, increased punitive culture and otherness of crisis now facing society. Faced this challenge, this paper presents the trajectory of criminology reviews and their ways, in order to start a new path, in order to propose confronting punitive discourse in academia and formal instances of control.
\end{abstract}

Keywords: Critical Criminology; Criminal Justice System; Left Realism; Latin-American Criminology; Brazilian Criminology.

\footnotetext{
${ }^{1}$ Doutora e Mestra em Direito, Estado e Constituição (UnB). Professora de Processo Penal e Criminologia do Centro Universitário de Brasília (UniCEUB). Líder do Grupo de Pesquisa “Criminologia do Enfrentamento" (UniCEUB). Distrito Federal (Brasil). E-mail: carolinacferreira@gmail.com
} 


\section{1 - O QUE É (ERA) CRIMINOLOGIA CRÍTICA?}

A Criminologia, ao longo de seu percurso histórico, já tentou responder a algumas perguntas: “quem é o criminoso?", “o que é o crime?”, “como se realiza a criminalização de determinados grupos sociais?", "por que o Sistema de Justiça Criminal opera seletivamente?”. No século XXI, as perguntas estão presas a um círculo vicioso, faltando-lhe fundamentos para novos questionamentos (ANITUA, 2008; BARATTA, 1995).

Tais questionamentos - geralmente associados a marcos teóricos da Filosofia, da Antropologia, da Sociologia e do Direito - reúnem-se no movimento genericamente denominado “Criminologia Crítica”, que ganhou projeção no final dos anos 1960 e no início dos anos 1970, aproveitando a oportunidade aberta pelos movimentos de reivindicação de direitos civis em países como Estados Unidos e Inglaterra. Sua função primordial é denunciar a seletividade do sistema penal, desmistificando-o, especialmente em relação à premissa de que pune todos de forma igual o que seria a "função declarada do Direito Penal" (ANDRADE, 2012), e de que o funcionamento do sistema penal é exemplar (BARATTA, 2002, p. 160-161).

Este movimento criminológico ganhou espaço entre os críticos da dogmática penal, com a finalidade de demonstrar que critérios biológicos - utilizados em práticas nazistas durante a Segunda Guerra Mundial - estavam totalmente superados (SWAANINGEN, 1999, p. 9). Para Anitua (2008, p. 657), a Criminologia Crítica tem como objetivo o desenvolvimento de um "anti-projeto", com o objetivo de romper com todos os paradigmas criminológicos anteriormente existentes.

Constatado este caráter oposicionista, a Criminologia Crítica tem múltiplas origens. Nos Estados Unidos da América, William Chambliss, Richard Quinney e Austin Turk foram alguns dos primeiros pesquisadores que se assumiram criminólogos críticos, nos anos 1960 (ANITUA, 2008, p. 658). O periódico Crime and Social Justice foi a primeira publicação sobre criminologia crítica lançada naquele país; hoje denominado Social Justice, ainda reúne publicações importantes para o campo criminológico (SHANK, 1999). Os estudos de Howard Becker, Ed Lement e Erwin Goffman também são considerados importantes bases para a Criminologia Crítica norte-americana, já que alteraram o objeto de estudo, antes concentrado no autor de crimes, para o meio social e, principalmente, para as instituições totais (SWAANINGEN, 1999, p. 10).

Na Europa, a discussão crítica se concentrou na Inglaterra (com a National Deviance Conference, liderada por Ian Taylor, Paul Walton e Jock Young), na Alemanha (por meio dos estudos de Fritz Sack, Gerlinda Smaus, Sebastian Scherer, entre outros) e na Itália (com Massimo Pavarini, Dario Melossi e Alessandro Baratta). Na América Latina, destacaram-se os pensamentos 
de Lola Aniyar de Castro, Rosa Del Olmo, Denis Szabo, Eugenio Raúl Zaffaroni, Santiago Mir Puig e José Luis Díez Ripollés; no Brasil, Nilo Batista, Vera Malaguti Batista, Juarez Cirino dos Santos e Ela Wiecko Volkmer de Castilho desenvolveram pesquisas e publicações no sentido de reforçar o pensamento criminológico crítico no Brasil (ANDRADE, 2012, p. 58-59; SWAANINGEN, 1999, p. 9-11).

\section{2 - AS DIFERENTES CRIMINOLOGIAS CRÍTICAS}

Definidos as autoras e os autores que representam esta forma de pensar, é importante dizer que as Criminologias Críticas possuem múltiplas origens, pontos comuns, mas, também, aspectos bastante divergentes, a começar de seus conceitos. Por isso, o uso do plural ao mencioná-las me parece mais adequado.

Alessandro Baratta explica que, para as Criminologias Críticas, a criminalidade passa a ser considerada um "bem negativo, distribuído desigualmente conforme a hierarquia dos interesses fixada no sistema sócio-econômico e conforme a desigualdade social entre os indivíduos" (BARATTA, 2002, p. 161). Assim, nota-se a consideração da Criminologia Crítica a partir do pensamento marxista, da definição de classes e da constatação da atuação dos aparelhos ideológicos de Estado (ALTHUSSER, 1999, p. 114-115) nos processos de criminalização. Estes são pressupostos que marcam todas as correntes da Criminologia Crítica.

Um primeiro conceito de Criminologia Crítica originou-se da New Criminology ("Nova Criminologia"); tal terminologia foi título de um livro publicado por Ian Taylor, Paul Walton e Jock Young, na Inglaterra, em 1973, com o objetivo de se afastar do que, à época, considerava-se Criminologia - a discussão das causas do crime e da criminalidade, considerando aspectos etiológicos e ecológicos. Os pressupostos da "Nova Criminologia" eram originários de concepções marxistas e rompiam claramente com as características da Criminologia Positivista. Segundo Taylor, Walton e Young, a intenção da "Nova Criminologia" (ou teoria radical do desvio) seria ter a liberdade de

questionar as causas não somente do crime, mas, também, das normas que, em um sentido primário, criam o crime - isto é, das normas legais. A aceitação não questionada de um dado sistema legal e dadas normas legais têm sido a tendência geral na criminologia positiva, e o resultado tem sido desastroso para as pretensões de cientificidade da criminologia. (TAYLOR; WALTON; YOUNG, 1980, p. 56)

Esta Criminologia Crítica se definiu como materialista, entendendo que, para sua construção, a análise do direito deveria ser marxista, "ao lado de uma explicação social” dos papéis da sociologia do direito e da concepção de crime nas sociedades capitalistas (TAYLOR; WALTON; 
YOUNG, 1980, p. 68). A intenção desta Criminologia Crítica foi desvendar os impactos do capitalismo na concepção de crime, criminoso e criminalidade na sociedade. Em 1975, os mesmos autores publicaram a coletânea de textos Critical Criminology ("Criminologia Crítica”), obra que, até os dias de hoje, é considerada referência.

Os autores desenvolveram uma teoria crítica ou radical do desvio, que se diferenciou das teorias conservadoras ou liberais desde seu método à sua finalidade. A teoria radical partiu da utilização de métodos empíricos - pesquisas com observação participante, análise de dados com objetivos de transformação da realidade (TAYLOR; WALTON; YOUNG, 1980, p. 19) - e que tivessem por finalidade promover mudanças no cenário estudado (TAYLOR; WALTON; YOUNG, 1980, p. 27). Os autores mencionaram a necessidade do desenvolvimento de uma criminologia socialista, que criasse mecanismos diferentes dos já conhecidos pelo sistema penal tradicional, para solucionar os conflitos sociais (TAYLOR; WALTON; YOUNG, 1980, p. 21).

Esta Criminologia, de cunho essencialmente marxista e assumida como teoria crítica social, ainda possuía grande relevância no campo; porém, como prática política, perdeu força na Europa, especialmente após a queda do Muro de Berlim (SWAANINGEN, 1999, p. 15). A "Nova Criminologia" recebeu algumas críticas, especialmente de David Downes e Paul Rock (1982), que consideravam a corrente radical de difícil acesso aos pesquisadores que pretendiam desenvolver pesquisas mais objetivas (como a análise de padrões de policiamento ou a incidência de crimes patrimoniais), pois, antes do início da execução de determinada pesquisa, tal corrente analisaria a viabilidade do estudo de tal objeto - e se tal objeto poderia ser estudado pela Criminologia Crítica ou não. Além disso, para Downes e Rock, a Criminologia Radical não sofreu mais críticas porque aqueles que não seguiam seus pressupostos simplesmente não a consideravam. No Brasil, Roberto Lyra Filho critica as conclusões de Taylor, Walton e Young, considerando-as “decepcionantes”, já que não descrevem ou explicam como seria o controle social formal em uma sociedade socialista (LYRA FILHO, 1979, p; 13).

\section{3 - EM BUSCA DE UMA CRIMINOLOGIA CRÍTICA LATINO-AMERICANA}

Na América Latina, a Criminologia Crítica ganhou força nos anos 1970, especialmente na Venezuela, com os estudos de Lola Aniyar de Castro e Rosa del Olmo, sob a influência dos estudos desenvolvidos por Alessandro Baratta. Vera Andrade (2012, p. 49-76) aponta que Baratta ofereceu aportes teóricos a criminólogos europeus e latino-americanos. Para tanto, o filósofo italiano indicava que, para o desenvolvimento de uma Criminologia Crítica latino-americana, seria importante 
reconhecer que os sistemas penais dos países desta região "importaram” modelos de controle penal europeus e as concepções positivistas das ideologias correcionalistas e de tratamento; reconhecendose tal herança, para Baratta, seria fundamental a oposição dos criminólogos latino-americanos à reprodução de modelos positivistas ou autoritários; também seria essencial a reflexão sobre a atuação política mais adequada a cada país. Baratta ainda ressalta que os pensamentos criminológicos latino-americanos, que ganharam força nos anos 1980, não perdem em complexidade e profundidade teórica aos estudos europeus e norte-americanos.

Ao longo de seus estudos, Alessandro Baratta elaborou teoria fundada numa Criminologia Crítica defensora de direitos humanos (BARATTA, 1984, p. 330) e, em outras produções, também entendeu que a transformação proposta pela Criminologia Crítica deve se realizar pela atuação de representantes das instâncias formais de controle, face à realidade da incessante criminalização de novas condutas, agravamento de penas e do expansionismo penal; a mesma intervenção é sugerida por Zaffaroni (2001a).

Na América Latina também se desenvolveu a “Criminologia da Libertação", especialmente a partir dos estudos de Lola Aniyar de Castro, em obra homônima; de cunho marxista, a teoria pretende desenvolver o pensamento criminológico na América Latina, considerando as complexidades da formação do controle penal na região e em cada um de seus países, e pretende a libertação "das estruturas exploradoras; especialmente, mas não exclusivamente, através de uma libertação da ocultação das relações de poder e do funcionamento mascarado dos interesses; libertação do discurso educativo, religioso, artístico, jurídico e criminológico, vinculados àquelas relações de poder" (ANIYAR DE CASTRO, 2005, p. 110).

Segundo esta teoria, não é possível reproduzir os padrões europeus em todo o continente, nem em todo um país, pois os graus de desenvolvimento político e social diferem muito uns dos outros; para aprimorar o pensamento criminológico na América Latina, a Criminologia da Libertação pretende estudar as contradições normativas dos Estados latino-americanos e aprofundar os estudos sobre os controles sociais formais e informais.

No encontro de juristas e pesquisadores que fundaram o Grupo Latino-Americano de Criminologia Crítica, no México, em 1981, a partir de uma proposta de Roberto Bergalli, deliberouse que seria necessária uma mudança epistemológica na Criminologia Crítica então desenvolvida para que fosse criada uma teoria crítica própria, que considerasse a realidade latino-americana com instrumentos metodológicos adequados para tal (ANIYAR DE CASTRO, 2005, p. 100-102). Avançando nas análises, o grupo formado no México se reuniu novamente em Medellín e 
compreendeu que seria mais adequado recortar a abordagem do controle social para, especificamente, o controle penal.

Como resultado das discussões, Lola Aniyar de Castro indica que a Criminologia da Libertação não desenvolveu uma "teoria criminológica latino-americana", pois o grupo de pesquisadores questionava o próprio conceito de Criminologia; além disso, desenvolver uma teoria criminológica não seria um objetivo condizente com as finalidades da Criminologia da Libertação, pois "as teorias não têm nacionalidade" (ANIYAR DE CASTRO, 2005, p. 107); cada país ou cada região de um país teria autonomia para desenvolver pensamentos críticos e, principalmente, medidas que envolvessem a diminuição e a mudança de estratégias relacionadas ao controle penal. A mesma autora enumerou os objetivos da Criminologia da Libertação:

[...] - a oposição à sociologia positivista;

- a importância da dialética (em vez da explicação causalista) e da totalidade como categorias analíticas e interpretativas, já que ambas contribuem para reconhecer os fatos como realmente são e para dar-lhes sua estrutura significativa;

- a importância dada à razão prática ou moral, isto é, à união entre filosofia e ciência;

- o que Horkheimer denominou "o conhecimento do mundo", ou, o que é a mesma coisa, o conhecimento dirigido pelo compromisso;

- a atitude frente ao poder e a crença nas possibilidades da transformação radical. (ANIYAR DE CASTRO, 2005, p. 109-110)

A Criminologia da Libertação estudou a política de drogas internacional, que afeta a América Latina, concentrando-se na situação da Venezuela, em suas primeiras pesquisas. A multiplicidade cultural e a história oral da América Latina (considerando, por exemplo, as concepções de "bem" e "mal" culturalmente repassadas em comunidades de todo o continente) também foram objetos de estudo (ANIYAR DE CASTRO, 2005, p. 112). A título de conclusão, Castro entendeu que os sistemas penais latino-americanos reproduziam as teorias de controle social formais e informais criadas na Europa, de forma mais acentuada em relação aos mais pobres. Castro constatou, assim, a seletividade do sistema penal, tão denunciada teoricamente pela Criminologia Crítica (ANDRADE, 2012, p. 285).

Para Massimo Pavarini (2006, p. 17-19), a Criminologia da Libertação foi uma corrente adequada para a América Latina, mas um tanto óbvia; para o autor, a teoria poderia ter se desenvolvido mais, para chegar ao caráter político da Criminologia nesta região: por que não refletir sobre a aproximação de diversos criminólogos com as políticas de recrudescimento do controle penal? Pavarini ainda demonstrou preocupação ao entender que a Criminologia da Libertação propõe a ligação dos criminólogos aos movimentos revolucionários - mais uma vez, a reflexão política deste processo não é realizada. E finalizou entendendo que apenas o grito de denúncia, como 
fez Lola Aniyar de Castro, aproximou a Criminologia da Libertação de uma "criminologia romântica" (PAVARINI, 2006, p. 19).

Também Rosa del Olmo, com “A América Latina e sua Criminologia”, explicou o processo de propagação do pensamento criminológico no continente, tanto em nível regional como em países como Argentina, Venezuela, México, Brasil, Equador, Cuba e Bolívia (DEL OLMO, 2004, p. 197288). Os países latino-americanos recepcionaram a Criminologia partindo do Positivismo europeu - e com certo atraso, pois as teorias positivistas já estavam sendo fortemente questionadas na Europa quando foram recebidas, por exemplo, no Brasil ${ }^{2}$. Tal influência positivista refletiu em diversos aspectos - desde a produção das normas até a concepção da Criminologia como ciência. Para tanto, ganhou forte respaldo da docência. No Brasil, Del Olmo destacou que médicos poderiam ministrar aulas de Criminologia nas Faculdades de Direito, demonstrando a familiaridade com a concepção positivista desta disciplina, que sequer era, nos anos 1970 , chamada de ciência ${ }^{3}$.

Com a continuidade das discussões, mudanças foram observadas nos discursos oficiais e não oficiais: os pesquisadores interessados na Criminologia ora se reuniram sozinhos, ora tinham a companhia de penalistas, que julgavam importantes os conhecimentos criminológicos para a implementação de políticas criminais; estas mudanças foram verificadas por Del Olmo, que analisou o conteúdo dos encontros realizados sobre Criminologia e Direito Penal na América Latina, especialmente entre os anos 1960 e 1978 (DEL OLMO, 2004, p. 257-288). Nota-se, nestes encontros, uma mudança de paradigmas e o aumento dos estudos que visassem ao desenvolvimento de alternativas à pena de prisão e às ideologias de tratamento, até então fortemente aplicadas e reconhecidamente fracassadas (DEL OLMO, 2004, p. 292).

Porém, o paradigma dominante no continente latino-americano continuou sendo o mais punitivo possível. Para Del Olmo, esta movimentação é típica "da crise do capitalismo e de suas necessidades de ajuste, destacando-se permanentemente ao longo da história os esforços de difusão continental, a incorporação dos conceitos e temas elaborados nos países desenvolvidos em suas diferentes instâncias históricas para enfrentar o problema do delito" (DEL OLMO, 2004, p. 262). A

\footnotetext{
${ }^{2}$ Sobre a recepção do pensamento criminológico etiológico (ou positivista) no Brasil, v. ALVAREZ, 2003 e FARIA, 2007.

${ }^{3}$ Para ilustrar a realidade descrita por Rosa Del Olmo, segue um excerto que explicita a sua pesquisa: "De acordo com um questionário enviado aos representantes mais destacados de nossa disciplina nos diversos países da América Latina, foi possível constatar a utilização dos mesmos tipos de manuais na maioria dos países que responderam ao questionário [...]. mas o que mais chama a atenção é que, dos onze países que responderam ao questionário, cinco utilizavam, em 1976, o Manual de Biologia Criminal, de Franz Exner, e quatro a Criminologia, de E. Mezger, os quais, como se recordará, foram escritos respectivamente em 1939 e 1933, embora tenham sido traduzidos anos depois" (DEL OLMO, 2004, p. 276).
} 
autora ainda criticou o uso de instrumentos metodológicos típicos do paradigma etiológico para a análise crítica do problema da expansão do sistema de justiça criminal na América Latina.

Por fim, não se pode deixar de mencionar a importância dos estudos de Eugenio Raúl Zaffaroni para o desenvolvimento de uma Criminologia Crítica de matriz latino-americana. No início dos anos 1990, na esteira das transformações propostas pela Criminologia da Libertação, Zaffaroni pensou em "táticas e estratégias" de contenção do poder punitivo na América Latina, propondo, em primeiro lugar, a inserção de discursos não violentos em instâncias informais de controle, especialmente nas universidades; também é importante, para o autor, "a neutralização do aparelho de propaganda violenta do sistema penal", ou seja, a contenção da mídia na propagação da cultura punitiva (ZAFFARONI, 2001a, p. 175 e 177). Uma terceira estratégia seria o emprego da “intervenção mínima como tática", utilizando-se sempre das medidas menos punitivas para reformas penais ${ }^{4}$. É importante dizer que, até hoje, Eugenio Raúl Zaffaroni continua sendo um dos grandes intelectuais das ciências criminais na América Latina.

\section{4 - O BRASIL NO CENÁRIO DAS CRIMINOLOGIAS CRÍTICAS}

No Brasil, Heleno Fragoso, Roberto Lyra Filho, Juarez Cirino dos Santos, Nilo Batista, Vera Malaguti Batista e Vera Regina Pereira de Andrade são nomes muito importantes para a recepção da Criminologia Crítica.

Roberto Lyra Filho deixou bastante claro que o objetivo da Criminologia Crítica deveria ser o abandono da "mania de 'definir o crime' no prólogo dos tratados, uma forma idealista e burguesa de pensar" (LYRA FILHO, 1979, p. 15). Ainda constatou que a Criminologia Crítica, até o final dos anos 1970, só tinha criticado seus objetos de pesquisa - o sistema de justiça, os processos de criminalização, qualquer outro campo de estudo que se relacionasse à criminalidade; além disso, alertou que a Criminologia Crítica, como desenhada até o final dos anos 1970, poderia se ater a um determinado ponto "infecundado", ou seja, sobre um objeto de pesquisa que não provocasse necessariamente uma discussão importante. Em oposição a esta constatação, Lyra Filho desenvolveu uma nova visão criminológica, por ele intitulada "Criminologia Dialética", "caracterizada pela visão dirigida constantemente para a totalidade e o devenir" (LYRA FILHO, 1979, p. 22). Em livro homônimo, defendeu que a Criminologia tradicional (positivista) frustrou-se, nos anos 1970, e “voltou a apelar para a ética”. Nesse sentido, para Lyra Filho, uma reflexão dialética é necessária

${ }^{4}$ Esta "estratégia" é utilizada até hoje nos sistemas legais latino-americanos. Este ponto será mais desenvolvido nos itens 1.2 e 2.2 deste trabalho. 
para reconhecer os valores fundantes de um pensamento criminológico crítico. Para tanto, o autor discutiu as noções de cultura e subcultura, de valor e de práxis e considerou a Criminologia Dialética um método de interpretação de questionamentos jurídico-penais, filosóficos e político-criminais (LYRA FILHO, 1972, p. 121-124).

Em 1979, Juarez Cirino dos Santos já se posicionava de forma bastante reflexiva em relação à influência do Positivismo Criminológico no Brasil em seu trabalho de Mestrado apresentado junto à Pontifícia Universidade Católica do Rio de Janeiro, intitulado "A Criminologia da Repressão: uma crítica ao positivismo em criminologia". O texto explicita as diferentes teorias criminológicas então existentes e a necessidade de se identificar os discursos de justificação do emprego da criminologia positivista para a discussão dos conceitos de crime e criminoso ${ }^{5}$, reconhecendo que esta exclui "a reação social dos aparelhos de controle e repressão social; a influência da rotulação como criminoso (e da estigmatização social) sobre a criminalidade futura", além de aprofundar-se na análise política do controle penal (SANTOS, 1981, p. 114-115).

Em 1981, o mesmo autor publicou “A Criminologia Radical” e realizou a missão de trazer ao Brasil o pensamento de Taylor, Walton e Young, mostrando a importância de sua aplicabilidade para revelar as contradições do sistema penal e sua obediência ao modo de produção capitalista (SANTOS, 1981, p. 87). Ao final de seu trabalho, Santos expôs a "política alternativa da Criminologia Radical”, que propôs “a penalização da criminalidade econômica e política das classes dominantes (ampliação do sistema punitivo) e a despenalização da criminalidade (típica) das classes dominadas (contração do sistema punitivo e substituição das sanções estigmatizantes" (SANTOS, 1981, p. 91). Também se propõe, no trabalho, a articulação dos movimentos dos presos com o dos trabalhadores, mudar a concepção da opinião pública sobre as questões relacionadas à criminalidade e "desenvolver o contrapoder proletário" (SANTOS, 1981, p. 91). Roberto Lyra Filho (1979, p. 11) elogiou as conclusões de Santos ao dizer que ele foi um dos únicos autores a superar "aquela espécie de niilismo que acarretaria não o desenvolvimento da Criminologia Crítica, mas a extinção da Criminologia, sem mais".

Segundo Vera Andrade (2012, p. 78), Juarez Cirino dos Santos expôs os pressupostos da teoria radical norte-americana e representou o "eixo teórico-crítico" de uma Criminologia Brasileira, ligado à construção de um pensamento de perspectiva marxista, que pode dialogar com o Direito

\footnotetext{
5 “As explicações causais do comportamento criminoso selecionam os fatores de determinação do comportamento (causas eficientes) e excluem o parâmetro valorativo constituído pelas definições legais de crime (causas formais), que confere ao comportamento o caráter de criminoso: não é possível explicar, previamente, a natureza, conteúdo e significação ideológica dos parâmetros jurídicos e políticos de valoração do comportamento social" (SANTOS, 1981, p. 114).
} 
Penal e o Processo Penal em igualdade de condições; de outro lado, Nilo e Vera Batista representam o "eixo histórico-científico", comprometido com a criação de uma Criminologia Crítica Brasileira, fundada no marxismo, que conseguiu desenvolver projetos de redução ou contenção do controle penal a partir dos anos 1980, mas, segundo a própria Vera Batista, em pequena escala, pois

O Brasil se policizou intensamente a partir da "transição democrática". É como se uma cultura punitiva de longa duração se metamorfoseasse indefinidamente. Mudam os medos, mas ele, o medo, permanece ali, dirigido aos mesmos de sempre, os do "lugar do negro". A tradução da conflitividade social em crime produziu, por um lado, o acirramento do estado de polícia. CPI's, vigilância, UPP's, controle territorial, a apologia da polícia de combate, o bom matador puro. Assim, a judicialização da vida privada caminha com a gestão policial da vida. (BATISTA, 2011, p. 114-115).

Assim, a corrente teórica que pode ser chamada de Criminologia Crítica Brasileira, ainda em formação, representa as reflexões realizadas sobre o controle penal e a justiça criminal, considerando-se, para tal, especialmente, os impactos da construção de um Estado Democrático de Direito fundado em perspectivas político-criminais ainda muito conservadoras.

\section{5- ENTRE REALISMOS DE DIREITA E DE ESQUERDA, AS "NOVAS CRIMINOLOGIAS"}

No final do século XX, o mundo passou por transformações que alteraram a concepção da Criminologia Crítica. Enquanto a América Latina passa por processos de redemocratização, os Estados Unidos da América e a Europa sofrem crises institucionais que, no campo da política criminal, traduzem-se no aumento da criminalização - primária, secundária e terciaria ${ }^{6}$. Tais mudanças determinaram um ajuste nos pensamentos criminológicos. Neste contexto, desenvolve-se uma nova corrente criminológica denominada "Realismo Criminológico", dividido em "Realismo de Direita" e "Realismo de Esquerda".

O Realismo de Direita se dedica ao desenvolvimento de pesquisas empíricas que possam auxiliar no desenvolvimento de políticas penais. Cria-se, no âmbito da Criminologia Crítica, nos anos 1990 e 2000, o "fetiche dos números": dados quantitativos seriam mais importantes do que a

\footnotetext{
${ }^{6}$ A criminalização primária consiste na seleção dos bens jurídicos considerados relevantes para a tutela penal. Tal seleção é feita, de forma geral, pelo Poder Legislativo; a criminalização secundária, por sua vez, consiste na seleção das pessoas que se submeterão ao sistema de justiça, na condição de investigadas/os ou rés/réus; a criminalização terciária, finalmente, consiste na execução da pena - uma dupla seleção, uma vez que a/o condenada/o já foi selecionada/o pelo sistema de justiça e, nesse momento, galga a posição de "condenada/o", para depois figurar como "egressa/o" do sistema penitenciário. Sua condição de cidadã/cidadão nunca mais será a mesma. Para mais discussões sobre os processos de criminalização, ver BARATTA, 2003.
} 
definição metodológica, e os criminólogos estariam muito mais preocupados em ajudar a elaborar políticas ${ }^{7}$ do que críticas. Tal corrente é representada por autores como James Wilson ${ }^{8}$, Ernest van den Hagg, Andrew von Hirsch e Travis Hirschi (PLATT; TAKAGI, 1977, p. 1-2) e defendem o aumento das punições, principalmente da pena de morte e da prisão como primeira resposta estatal. Os autores acima mencionados desenvolvem pesquisas para desconstituir o caráter seletivo do sistema penal, defendendo, por exemplo, que um baixo índice de QI seria mais importante para a prática de crimes como critérios como raça ou classe (PLATT; TAKAGI, 1077, p. 2). O Realismo de Direita foi bastante fecundo nos anos 1970 e 1980, vindo ao encontro das políticas criminais de expansão do sistema penal na Europa e nos Estados Unidos. Observa-se, aqui, uma retomada de investigações sobre as "causas" do crime, ou seja, do paradigma etiológico (ANITUA, 2008, p. 718). Para os defensores da "Nova Criminologia", o Realismo nada mais é do que uma vertente conservadora da teoria criminológica (TAYLOR; WALTON; YOUNG, 1980, p. 47), que não se preocupa com aspectos como a legitimidade dos representantes das instâncias de controle penal ${ }^{9}$.

O Realismo de Esquerda foi representado por autores como Jock Young, Roger Matthews, Ray Pawson e Nick Tilley, que defendiam a resistência do pensamento criminológico crítico frente à expansão do pensamento autoritário e expansionista em relação ao crime. Tendo em vista a origem marxista desta nova teoria, autores como Gabriel Anitua (2008) associam a Criminologia Radical ao Realismo de esquerda, enquanto que, especialmente para os autores britânicos e norteamericanos, o Realismo é originário da Criminologia Radical, mas possui características diferenciadas (PAVLICH, 1999). George Pavlich resume o Realismo de Esquerda à crítica aos "idealistas de esquerda" (antigos realistas), por estes terem levado muito a sério questões

\footnotetext{
${ }^{7}$ Neste período, ensaios e artigos que se iniciam com a expressão "what works" ("o que funciona”) se tornam muito comuns.

${ }^{8}$ James Wilson ficou conhecido nos campos criminológico e político-criminal como um dos entusiastas da "Broken Windows Theory" ("Teoria das Janelas Quebradas"), em texto largamente divulgado nos anos 1970 (WILSON; KELLING, 1982). Autores como Anitua e Young o aproximam mais da "Administrative Criminology" ou "Criminologia Atuarial" do que do Realismo de Direita. A Justiça Atuarial - ou "Criminologia Administrativa", segundo Anitua (2008, p. 814) - desenvolveu-se na Europa, na metade da década de 1980, e consiste no tratamento do sistema de justiça criminal de forma "profissionalizante", "administrativizante". Considerando o contexto de uma sociedade de risco, seria mais importante do que a definição de crime, criminoso ou da criminalidade a análise da "funcionalidade" do sistema de justiça criminal, com a elaboração de dados estatísticos e projeções que o tratem pragmaticamente. René van Swaaningen (1999, p. 16) menciona que o atuarialismo seria fundado na desconsideração de questões morais e na conversão dos problemas do sistema de justiça criminal em "questões técnicas de implementação".

${ }^{9}$ Taylor, Walton e Young criticam Paul Tappan e Austin Turk, que mencionam ser suficiente à análise criminológica a legalidade das normas, sem se questionar a posição das autoridades e o contexto de seu reconhecimento como tal: "[...] para nós, e para outros criminólogos radicais, as questões de como autoridades se tornam autoridades, e os modos pelos quais elas transformam legitimidade em legalidade, é central; pois, a menos que estas questões sejam compreendidas, nós seremos deixados, certamente (com Turk), com uma visão inevitabilista da sociedade burguesa. Uma precondição para uma criminologia radical é a separação do essencial do não-essencial, a historicidade-específica da historicidadeinevitável" (TAYLOR; WALTON; YOUNG, 1980, p. 58).
} 
relacionadas ao crime, dando espaço a criminólogos correcionalistas encamparem seus projetos conservadores; o mesmo autor reflete que o Realismo Criminológico, mesmo partindo de pressupostos socialistas, não conseguiu se realizar em contextos locais - restringiu-se, assim, ao debate teórico (PAVLICH, 1999, p. 33).

Segundo Matthews (2009, p. 356 e 358), “a Criminologia Realista tem por pressuposto a ligação entre teoria, método e política de implementação de propostas, de forma coerente e consistente". Assim, os objetos de estudo do Realismo de Esquerda são mais amplos do que os da Criminologia Radical; a intervenção política é cada vez mais considerada. Máximo Sozzo entende que esta necessidade de ser "relevante politicamente" fez com que a Criminologia Realista buscasse respostas teóricas que sacrificaram o "pensar sem limites" próprio da Criminologia Crítica dos anos 1960 e 1970 (SOZZO, 2006, p. 10).

Eugenio Raúl Zaffaroni elabora uma teoria denominada "realismo jurídico-penal marginal", fundada nos ensinamentos de Alessandro Baratta e voltada à situação de extrema violação a direitos humanos na América Latina. Por isso, a definição de "marginal" do autor significa exatamente a aplicação do direito penal àqueles que se encontram à margem da proteção do Estado, aos que não se beneficiam de políticas públicas de proteção social. Aos “marginais”, o sistema penal mostra toda a sua força e eficiência (ZAFFARONI, 2001, p. 172). Zaffaroni defende que a resposta marginal deve ser dada por todos os componentes das instâncias formais e informais de controle ${ }^{10}$ tal resposta é um imperativo ético àqueles representantes das instâncias formais e deve ser realizada de forma positiva (e propositiva), para que o sistema penal tenha por objetivo sua sucessiva redução.

Alessandro Baratta (2006, p. 151) compreendeu que a Criminologia Crítica não é capaz de se ocupar com todos os problemas relacionados do controle penal, formal ou informal; é necessário que os criminólogos críticos ocupem espaços coletivos de construção do discurso para a elaboração de novas respostas à "questão criminal”, de forma a superar o paradigma etiológico ${ }^{11}$.

\footnotetext{
10 "Ser juiz ou catedrático na América Latina significa haver ultrapassado, previamente, muitos riscos: haver nascido (isto é, não ter sido abortado), haver sido alimentado adequadamente, haver superado ou escapado das doenças infantis com sequelas incapacitantes, haver conseguido alfabetizar-se e, ainda mais, haver ascendido aos níveis médio e superior do ensino, haver escapado das ameaças à vida adulta que os fenômenos naturais catastróficos representam, a violência política e não política, não haver 'desaparecido', etc., e outro sem-número de fatores cujo conjunto compõe o milagre que coloca tal indivíduo numa situação extremamente privilegiada. Do alto deste milagre privilegiante, basta olhar ao redor para notar que foram muitos aqueles que frustraram sua esperança de vida ou aqueles que, sem frustrá-la, de modo algum puderam sequer aproximar-se dessa situação de privilégio. [...] Diante desta constatação, um operador consciente não pode deixar de vivenciar a possibilidade de que este milagre acabe no segundo seguinte, de que, para além da consideração metafísica da morte, em nossa região marginal há uma aceleração da morte que está muito abaixo desta consideração universal e que este fenômeno, em sua posição milagrosa, compromete este agente com a vida no sentido de exigir-lhe uma resposta à violência que torne sua existência menos milagrosa e sua posição menos privilegiada." (ZAFFARONI, 2001, p. 153-154)

${ }^{11}$ Sobre a diferenciação entre o paradigma etiológico e o paradigma da reação social, v. ANDRADE, 1996.
} 
Como exemplo destas "novas criminologias", que ainda têm por característica o questionamento de estruturas sociais e de poder, tem-se a inserção de um olhar de gênero às Criminologias, iniciada nos anos 1970, dada a posição desigual da mulher no sistema penal, quer esta fosse autora ou vítima de delitos (BARATTA, 1999, p. 19). Para abordar esse paradigma, antes é preciso pensar no conceito de gênero, especialmente em contraposição à categoria "sexo", de cunho biológico. Joan Scott (1999) demonstrou a afirmação deste conceito como categoria analítica, histórica, a qual, numa concepção mais moderna, inclui não só sexo, mas também classe e raça - de acordo com uma concepção crítica da interlocução destas três categorias -, para que se desenvolva a reflexão sobre o processo de visibilização da mulher como participante ativa dos processos políticos e sociais, estabelecendo, ainda, estratégias do movimento feminista para a tutela de seus direitos. Assim, gênero, numa concepção atual, pressupõe uma construção social (SCOTT, 1999, p. 200; BARATTA, 1999, p. 23; BUTLER, 2010), uma nova forma de ressignificar as relações sociais e, especialmente, o Direito ${ }^{12}$.

Afirmando o conceito de gênero, é importante reconhecer o Feminismo como movimento plural, com premissas e lutas específicas. Logo, não é possível entender a existência de um único Feminismo, mas de múltiplas correntes que se dividem nos planos teórico (da construção de teorias sobre gênero ${ }^{13}$, participação política das mulheres ${ }^{14}$ e os processos de criminalização a elas aplicáveis, tanto no plano da vitimização como da sua crescente criminalização ${ }^{15}$ ) e prático, na militância feminista (em movimentos pela legalização do aborto no Brasil, pela diminuição da violência contra a mulher, pela diminuição das desigualdades nas relações de trabalho, dentre outras pautas ${ }^{16}$. Para compreender o espaço político da militância, é importante mencionar Judith Butler (2010, p. 19), que defende não ser possível definir a categoria "mulheres" como instrumento teórico;

\footnotetext{
${ }^{12}$ Sobre o assunto, Camilla de Magalhães Gomes, em tese de Doutorado a ser defendida na Faculdade de Direito da Universidade de Brasília, tem se dedicado sobre as relações entre gênero e direito e as dificuldades deste, enquanto "ciência", de lidar com a ausência de categorias, especialmente em situações que fogem à heteronormatividade. Enquanto o trabalho não está concluído, a respeito das relações entre Criminologias e Feminismos, ver GOMES, 2012. ${ }^{13}$ Para a discussão de teorias de gênero, ver, dentre outras, SAFFIOTI, 2004; SCOTT, 1999; BUTLER; SCOTT, 1992; BUTLER, 2007.

${ }^{14}$ Para a discussão sobre a participação política das mulheres numa sociedade patriarcal, ver, dentre outras, PATEMAN, 1989.

${ }^{15}$ No Brasil, as dificuldades em relação às questões de gênero ainda são diversas. Com o advento da Lei Maria da Penha (Lei $\mathrm{n}^{\mathrm{o}}$ 11.340, de 7 de agosto de 2006) e alterações no Código Penal realizadas pela Lei $\mathrm{n}^{\circ}$ 12.015, de 7 de agosto de 2009, que passou a definir o crime de estupro e outros delitos como "crimes contra a dignidade sexual", substituindo a obsoleta definição "crimes contra os costumes", o tema da violência contra a mulher passou a ser mais debatido. Com isso, os registros no sistema de justiça criminal aumentaram consideravelmente - não se pode inferir se o aumento nos dados se deu pelas recentes alterações legislativas ou se, de fato, a mulher tem se reconhecido como sujeito de direitos. ${ }^{16}$ Sobre os espaços de militância, a Marcha das Vadias, movimento mundial que ocorre desde 2011, é um bom exemplo. Sobre o assunto, ver FERREIRA, 2012.
} 
porém, é possível defini-la no campo político, como primeiro - mas não único - sujeito dos Feminismos.

Portanto, é bastante difícil nomear uma só Criminologia Crítica Feminista, já que as Criminologias Críticas e os Feminismos são sempre plurais e diversificados; assim, as possibilidades de interseção são múltiplas. Tomando, assim, a pluralidade no emprego, as Criminologias Críticas e os Feminismos estudam, dentre outros objetos, o papel da mulher no sistema de justiça criminal. Para tanto, é importante reconhecer o androcentrismo do sistema penal - as leis penais e processuais penais foram e são discutidas, exclusiva ou majoritariamente, por homens, que são os detentores "naturais" do espaço público, enquanto as mulheres ocupam majoritariamente os espaços privados da sociedade; o sistema de justiça criminal, posicionado no espaço público, ainda é majoritariamente ocupado por homens. Vera Andrade (2012, p. 143-144) demonstra que o sistema penal individualiza o homem e "coisifica" a mulher: o sujeito ativo de um crime é sempre um "cara" (masculino), e a vítima é sempre uma "coisa" (feminina).

A atuação das Criminologias Críticas e dos Feminismos se dá em espaços nos quais as mulheres são vítimas - em casos de violência doméstica e violência sexual, por exemplo - ou autoras - praticantes de crimes previstos em toda a legislação penal; no âmbito da execução penal, a origem e o aumento da população carcerária feminina também é objeto de diversos estudos recentes ${ }^{17}$. Mantendo sua origem crítica, estes olhares são atuais exemplos de desconstrução de discursos e estruturas, com o objetivo de reafirmar sua importância para a efetivação dos direitos das mulheres.

Também reconheço ser impossível refletir sobre o sistema de justiça criminal, em especial o sistema carcerário, sem mencionar o racismo. Ana Luiza Pinheiro Flauzina denuncia, há muito, o genocídio da população negra, em especial de sua juventude (FLAUZINA, 2006; FREITAS; FLAUZINA; PIRES; VIEIRA, 2014).

Ao fim, reconheço a minha atual limitação em trabalhar com a categoria de raça. Talvez tal incompetência seja consequência de um ensino jurídico branco, cisgênero, heteronormativo, machista e racista, originado de um positivismo que nunca serviu para discutir as questões brasileiras. Evidenciar o racismo no sistema de justiça criminal, assim, parece até ser ingênuo. É necessário que se reflita sobre estratégias de contenção do poder punitivo em relação aos negros e, para falar com Camila Prando (2015), encontrar epistemologias que façam com que as Criminologias Críticas, pensadas e discutidas desde os anos 1970 por homens brancos, que tratam

17 Como exemplos destes estudos, ver CERNEKA; JESUS FILHO; MATSUDA; NOLAN; BLANES, 2012; LOURENÇO; DUARTE; LINO; CAMPOS, 2009; CASTILHO, 2008; ANGOTTI, 2012; ESPINOZA, 2004; GARCIA, 2001. 
os corpos negros como objetos - corpos mortos - repensem sua abordagem e dialoguem com todos os sujeitos, com a dignidade que merecem. Para tanto, a leitura de autoras negras, feministas, criminólogas, se faz urgente e necessária, sob pena de se reproduzir os discursos das Criminologias Críticas tão ouvidos nos anos 1960.

Retomando as concepções gerais sobre um "futuro" das Criminologias Críticas, Vera Andrade entende que o atual movimento criminológico crítico observado na América Latina e, em especial, no Brasil, adquire "o sentido de um movimento de resistência” (ANDRADE, 2012, p. 94). No mesmo sentido, Lola Aniyar de Castro, em palestra ministrada em São Paulo, em 2008, disse que, diante de tantas violações a direitos humanos ocorridas no século XXI, e diante da expansão do sistema penal como política de Estado em muitos países do mundo, as Criminologias Críticas devem tomar a posição de defensora de garantias mínimas - logo, não é o momento para movimentos mais intensos, sob o risco de se deslegitimar totalmente o pensamento crítico (ANIYAR DE CASTRO, 2008).

Assim, quase todas as "Criminologias Críticas" apresentadas acima se posicionam à esquerda, na análise do controle penal, mas são frequentemente questionadas: a crítica criminológica se resume à simples contestação? Que propostas traz(em) a(s) Criminologia(s) Crítica(s)? Quais são as soluções para o Direito Penal e para o próprio cárcere: diminuir ou aumentar o seu âmbito de proteção (LARRAURÍ, 1992, p. 209) ${ }^{18}$ ? Neste ponto, Elena Larraurí (1992, p. 194) explicou que a Criminologia Crítica, tal como desenhada, também não conseguiu representar reivindicações de determinados movimentos sociais, como é o caso do movimento feminista, dos grupos ambientais, que não se sentiam, nos anos 1980, nem "à direita" e nem "à esquerda".

A primeira crítica que leva a Criminologia Crítica à crise é de cunho teórico: Paul Hirst, já em 1982, tentava separar marxismo de teorias sobre crime e desvio. Hirst problematiza uma possível “abordagem" marxista sobre os estudos de crime e desvio, objeto da Criminologia Crítica, e expressa textualmente que "crime e desvio desaparecem dentro das preocupações teóricas gerais e do objeto científico específico do marxismo. Crime e desvio não são mais um campo científico para o

\footnotetext{
${ }^{18}$ É curioso perceber que, desde os anos 1970, a excessiva produção legislativa para solucionar problemas relacionados aos crimes e à criminalidade constitui objeto de estudo dos criminólogos. Taylor, Walton e Young (1980, p. 71) demonstram que "[...] a mais desconcertante questão para as sociologias do direito existente é a questão de porque a mudança legislativa deveria ocorrer absolutamente (a pressão por mudança sendo vista para ser explicada suficientemente por referência à existência (inexplorada) de um interesse social e suas necessidades). Nenhuma resposta é disponível, nesses enfoques, para a questão de por que novas leis (como aquelas regulando a organização da justiça juvenil) seriam relativa e recentemente necessárias, e o que é que, sobre o período em que tais leis são criadas, é primeiramente conducente à sua criação".
} 
marxismo do que educação, família ou esporte” (HIRST, 1980, p. 250). Anitua também descreveu a crítica de Hirst em outra obra, "A lei e a ideologia":

[...] o marxismo deveria cancelar a criminologia, pois quando dedicava-se ao estudo do modo de produção, da luta de classes, e ao Estado e a ideologia como suportes superestruturais, fazia-o com o objeto de abolir a estrutura que nesse período histórico recorreu ao delito e à criminologia para perpetuar-se. Por conseguinte, a criminologia não pode ser senão conservadora, e em compensação um crítico, radical e sobretudo marxista, não pode ser "criminólogo". (ANITUA, 2008, p. 688)

Pavlich (1999), mais adiante, tentou desconsiderar tal crítica, fundamentando que, como o crime possui uma grande relação com o modo de produção capitalista, poderia ser objeto de uma análise materialista, ainda que Marx não tenha se manifestado expressamente sobre questões relacionadas ao controle penal.

Continuando com as críticas às Criminologias Críticas, René van Swaaningen (1999) expôs que, durante os anos 1970, houve o total entrosamento entre, principalmente, jurisprudência e os movimentos criminológicos europeus; com os resultados colhidos por esta interação, houve um movimento de manutenção desta ordem, que mais se assemelhou a um retorno ao paradigma criminológico positivista, consistindo na prevalência do Realismo de Direita. Neste momento, a Criminologia Crítica entra novamente em crise; a posição de revolta e de questionamentos por mudanças políticas e sociais modifica-se totalmente, com a adoção de posturas de apoio político, principalmente a medidas que impunham "lei e ordem", contraditórias aos ideais anteriormente propostos pelos criminólogos críticos. Assim, o que antes era visto como vanguarda, ao final dos anos 1980 considerou-se um retrocesso - "um diletantismo acadêmico, com morais vitimizantes e políticas excêntricas" (SWAANINGEN, 1999, p. 15), auxiliando, assim, a legitimação do movimento expansionista. O autor também indicou que, curiosamente, a Criminologia Crítica foi vítima de seu próprio discurso, pois suas reivindicações nos anos 1970 (leis penais específicas para o tratamento da corrupção, de crimes ambientais, abuso sexual, genocídio) foram atendidas nos anos 1980; assim, o conteúdo crítico da Criminologia Crítica caiu no discurso mainstream (SWAANINGEN, 1999, p. 15).

Alessandro Baratta, em artigo publicado no Brasil em 1981, declarou que, naquele momento histórico, a Criminologia Crítica se preocupava muito mais com a análise dos sistemas jurídico-penais vigentes do que propriamente com as questões criminológicas surgidas. A Criminologia contemporânea tenderia a "transformar-se de uma teoria da criminalidade em uma teoria crítica e sociológica do sistema penal” (BARATTA, 2000, p. 35-36), dada a inoperância e falta de argumentos contrários ao recrudescimento crescente, à época, nos sistemas penais, 
principalmente naqueles em que se viviam regimes militares ou de exceção. Zaffaroni também afirmou não existir um discurso criminológico hegemônico porque, em fins do século XX e início do século XXI, não existe, também, um poder hegemônico; como os discursos criminológicos possuem uma estreita ligação com os discursos políticos, não se pode identificar tão facilmente uma corrente ou um pensamento atualmente dominante (ZAFFARONI, 2001b, p. 951-952).

Desde então, conclui-se que a Criminologia Crítica anda em círculos: ficou "presa" ao debate sobre a seletividade do sistema de justiça criminal e ao método empírico associado às Ciências Sociais (na realidade, a novidade seria apenas para o Direito, no campo metodológico) e suas propostas formuladas foram desconstituídas e "abafadas" por políticas públicas punitivas, de lei e ordem e expansão do sistema penal.

\section{6 - OS LIMITES DAS CRIMINOLOGIAS CRÍTICAS: O QUE FAZER?}

Uma "justificativa" para a falta de avanços dos pensamentos criminológicos críticos guarda natureza epistemológica: as Criminologias Críticas erraram ao utilizar apenas a denúncia e o diagnóstico. Poucos teóricos reconhecem este erro, e, quando o fazem, não conseguem sair deste círculo vicioso porque a estrutura do pensamento criminológico crítico não permite isto; um método altamente questionador, ironicamente, não permite respostas. Neste impedimento, a chamada “moderna Política Criminal”, que ganhou espaço nos anos 1990 - mais propositiva, mas, por outro lado, mais punitiva - ocupa o lugar da Criminologia Crítica.

Segundo Larraurí, a Criminologia Crítica passa por crises a partir dos anos 1980 por se restringir ao diagnóstico da seleção do sistema penal, da falta de proporcionalidade entre penas, da discricionariedade da atuação dos componentes das instâncias formais de controle. Além disso, seus marcos teóricos se dividem em pequenas correntes, quase ilhas; grupos representantes de movimentos sociais invisibilizados até então (ambientalistas, feministas, pacifistas) começam a defender a criminalização de determinadas condutas, ainda que de forma simbólica.

Uma segunda justificativa para a crise da Criminologia Crítica é paradoxalmente um mérito: teóricos de vários tipos se identificaram como "criminólogos críticos"; porém, a diversidade é tanta que pode haver aqueles que defendem desde o controle penal mínimo até as hipóteses de abolicionismo do sistema penal. É certo que os últimos estão em fase de extinção, considerando-se a morte de Louk Hulsman e o recente posicionamento de Nils Christie (2011), que defende mais o minimalismo penal do que o abolicionismo. 
Talvez não seja coincidência o fato de que as grandes referências em Criminologia, na atualidade, sejam escritas em espanhol: criminólogos espanhóis e latino-americanos vêm tentando renovar as perspectivas de uma Criminologia para a América Latina, marginal, preocupada com os nossos problemas mas, principalmente, focada nos discursos políticos locais, sem soluções europeias, exógenas (ZAFFARONI, 2011, p. 559-560).

O rumo da Criminologia, hoje, é ainda mais múltiplo do que no início dos anos 1970. Em meio a Criminologias ainda Críticas, ainda da Reação Social, e mais Atuariais (WILSON, 1982; DIETER, 2013), Culturais (FERRELL, 1995; CARVALHO et al, 2011), Anti-Criminologias (CARVALHO, 2013) ou Cautelares (ZAFFARONI, 2011), não temos apenas um pensamento criminológico crítico.

Em meio a esta pluralidade, vive-se um paradoxo nas Criminologias Críticas: busca-se a diminuição da punição em relação a determinados crimes - como, por exemplo, é o caso dos crimes patrimoniais e do tráfico de drogas, responsáveis pela maioria da população carcerária brasileira ${ }^{19}$ , mas as mesmas categorias "nem à esquerda e nem à direita" buscam a criminalização de certos comportamentos (como, por exemplo, a homofobia). Cria-se, assim, uma contradição: é possível admitir-se, seguindo o movimento criminológico crítico, que o Direito Penal possua função simbólica em algumas situações? Como fazê-lo, se a própria Criminologia Crítica indica que sua atuação é seletiva e não satisfaz às funções históricas de prevenção geral e especial dos crimes e da criminalidade?

Vera Malaguti Batista, após citar autores de correntes criminológicas críticas, conclui que "a criminologia se relaciona com a luta pelo poder e pela necessidade de ordem" (BATISTA, 2011, p. 19). Assim, da Inquisição às Criminologias Críticas (aí incluídas as novas formas, como a Criminologia Cultural e as Criminologias Feministas), o controle, a ordem e a punição são os objetos de pesquisa ou as finalidades maiores dos pensamentos criminológicos. Porém, a pergunta que se faz, em pleno século XXI, é a seguinte: a Criminologia Crítica, especialmente após o encarceramento em massa observado em países como Estados Unidos, Rússia e Brasil (WACQUANT, 2007), ainda tem a monótona função de diagnosticar o óbvio? Quais seriam os novos objetivos da Criminologia Crítica, em meio a políticas de "tolerância zero" (ANITUA, 2008, p. 785) e de inflação legislativa?

\footnotetext{
${ }^{19}$ Pessoas presas que respondem a processo ou foram condenadas por crimes contra o patrimônio somavam 97.206 pessoas em junho de 2014; em relação ao tráfico de drogas, esse número chegou a 66.313 pessoas; considerando o universo dos dados apurados pelo Departamento Penitenciário Nacional (BRASIL, 2015), somando-se as duas populações, chegamos a um percentual de 50,33\% de pessoas presas por apenas dois grandes bens jurídicos tutelados ("patrimônio" e "saúde pública").
} 
As Criminologias Críticas já mencionaram que o sistema de justiça criminal não é só instrumental, mas seletivo, simbólico: encampa discursos generalizantes e moralizantes, mas sua atuação é seletiva, restrita e discricionária. Pensando com os marcos teóricos representantes da Criminologia Crítica, sabe-se que tais características são complementares. Ao se enfatizar demais a criminalidade e a necessidade de punição, políticos (e até mesmo sociedade) negam-se a criticar a seletividade do sistema, ainda o legitimando. Em outras circunstâncias, os discursos encontram limites no âmbito de aplicação do sistema penal a um sistema de garantias institucionalizadas - no caso do Brasil, na Constituição -, mas que estão longe de serem efetivadas. A respeito disso, Vera Andrade (2012, p. 100) faz uma importante constatação:

o desafio é, então, não permitir que o criticismo se esgote no garantismo, ou que este colonize aquele, desafio redobrado sobretudo em tempos de barbárie punitiva, em que tanta energia tem de ser desgastada na luta "contra" o poder punitivo e a violação de direitos, e em que o garantismo parece de fato exercer uma sedução política sem precedentes na história das ideias penais, que a todos abriga numa acolhedora, confortável e às vezes imobilizadora bandeira progressista.

A angústia de Andrade é de que os pensamentos criminológicos críticos atuais limitem-se à crítica sobre o funcionamento do sistema penal - e consequente inconstitucionalidade de sua atuação - e não avancem a medidas descarcerizantes, descriminalizadoras e, principalmente, abolidoras do próprio sistema penal. Salo de Carvalho (2013) também expõe a mesma preocupação e, dialogando com Lola Aniyar de Castro, entende que o caminho possível para efetivas intervenções das Criminologias Críticas consiste na proteção dos direitos humanos, chegando ao que se denominou "criminologia da práxis" 20.

Assim, mesmo em crise, ainda se fala - e muito - nas Criminologias Críticas. Em tempos de funcionalismos, abolicionismos e minimalismos no Direito (ANDRADE, 2012), os pensamentos criminológicos ganham espaço no campo da Política Criminal, auxiliando na orientação de políticas públicas ligadas à questão criminal. Portanto, a Criminologia Crítica ainda precisa ter uma função provocadora, de desconstrução de questões postas ou tidas por "solucionadas". A Criminologia Crítica, ainda que em fase de resistência ou de posicionamento em "trincheiras" contra o aumento desenfreado do controle penal, é importante instrumento de questionamento da desigualdade e

\footnotetext{
20 "Na agenda dos direitos humanos, a criminologia crítica parece reencontrar um rumo bastante definido, hábil, inclusive, para excluir determinadas tendências utilitaristas com forte inspiração punitivista que procuram sustentar (legitimar), desde um discurso aparentemente crítico, a intervenção punitiva e a preponderância dos poderes em detrimento dos direitos - algumas (re)interpretações (criminalizadoras) do pensamento garantista operam exatamente nesse sentido. Assim, além de um campo teórico revitalizado e aberto aos movimentos sociais, a criminologia crítica como criminologia dos direitos humanos, nos termos propostos por Lola Aniyar de Castro, abre espaço, igualmente, para intervenções político-criminais, concretizando esta necessidade visceral de contato com a realidade social (criminologia da práxis)" (CARVALHO, 2013, p. 288).
} 
inoperância do sistema penal, da estrutura de classes, e de desenvolvimento de propostas. É tempo de superar os questionamentos teóricos e partir a campo, com instrumentos metodológicos adequados, para ocupar espaços nos debates políticos e sociais ligados às questões criminais.

\section{REFERÊNCIAS}

ALTHUSSER, Louis. Ideologia e Aparelhos Ideológicos de Estado (notas para uma investigação). In: ŽIŽEK, Slavoj. Um mapa da ideologia. Trad. Vera Ribeiro. $1^{\text {a }}$ reimpressão. Rio de Janeiro: Contraponto, 1996, p. 105-142.

ANDRADE, Vera Regina Pereira de. Do paradigma etiológico ao paradigma da reação social: mudança e permanência de paradigmas criminológicos na ciência e no senso comum. Revista Brasileira de Ciências Criminais. São Paulo, 1996, n. 14, p. 276-287.

Revan: 2012.

Pelas mãos da Criminologia: o controle penal para além da (des)ilusão. Rio de Janeiro:

ANIYAR DE CASTRO, Lola. Criminologia da Libertação. Trad. Sylvia Moretzsohn. Rio de Janeiro: Revan, 2005.

. Criminologia Crítica do século XXI como Criminologia dos Direitos Humanos. Palestra ministrada no $14^{\circ}$ Seminário Internacional do Instituto Brasileiro de Ciências Criminais. São Paulo, 26 de agosto de 2008.

ANITUA, Gabriel Ignacio. Histórias dos pensamentos criminológicos. Trad. Sérgio Lamarão. Rio de Janeiro: Revan, 2008.

BARATTA, Alessandro. Criminologia Crítica e crítica do direito penal. Trad. Juarez Cirino dos Santos. Rio de Janeiro: Revan, 2002.

Nuevas reflexiones sobre el modelo integrado de las ciencias penales, la política criminal y el pacto social (1998). In: BARATTA, Alessandro. Criminología y sistema penal. Buenos Aires: Euros Editores S.R.L, 2006, p. 168-198.

- ¿Tiene futuro la criminología crítica? (1995) In: BARATTA, Alessandro. Criminología y sistema penal. Buenos Aires: Euros Editores S.R.L, 2006, p. 112-138.

BARTLETT, Katherine T. Métodos jurídicos feministas. In: FERNÁNDEZ, Marisol; MORALES, Félix. Métodos feministas en el Derecho: aproximaciones críticas a la jurisprudencia peruana. Lima: Palestra Editores, 2011, p. 19-116.

BATISTA, Vera Malaguti. Introdução crítica à Criminologia Brasileira. Rio de Janeiro: Revan, 2011.

BUTLER, Judith. Problemas de gênero: feminismo e subversão da identidade. Trad. Renato Aguiar. Rio de Janeiro: Civilização Brasileira, 2010. 
CARVALHO, Salo de. Criminologia crítica: dimensões, significados e perspectivas atuais. Revista Brasileira de Ciências Criminais. São Paulo, 2013, v. 104, p. 279-295.

CHRISTIE, Nils. Uma pequena quantidade de crime. Trad. Rafael Nascimento. Rio de Janeiro: Revan, 2011.

DEL OLMO, Rosa. A América Latina e sua criminologia. Trad. Francisco Eduardo Pizzolante e Sylvia Moretzsohn. Rio de Janeiro: Revan, 2004.

DIETER, Mauricio Stegemann. Política criminal atuarial: a Criminologia do fim da história. Rio de Janeiro: Revan, 2013.

FLAUZINA, Ana Luiza Pinheiro. Corpo negro caído no chão: o sistema penal e o projeto genocida do Estado brasileiro. Rio de Janeiro: Contraponto, 2008.

FLAUZINA, Ana; FREITAS, Felipe; VIEIRA, Hector; PIRES, Thula. Discursos negros: legislação penal, política criminal e racismo. Brasília: Brado Negro, 2015.

LARRAURÍ, Elena. La herencia de la criminología crítica. 2ª ed. Espanha/México, 1992.

LYRA FILHO, Roberto. Carta aberta a um jovem criminólogo: teoria, práxis e táticas atuais. Revista de Direito Penal. Rio de Janeiro, v. 28, 1979, p. 05-25. Criminologia Dialética. Rio de Janeiro: Borsoi, 1972.

MATTHEWS, Roger. Beyond "so what" criminology: rediscovering realism. Theoretical Criminology, 2009, n. 13, p. 341-362. DOI 10.177/1362480609336497.

O mito da punitividade revisitado. In: MACHADO, Bruno Amaral (coord). Justiça Criminal e Democracia II. São Paulo: Marcial Pons; Brasília: Fundação Escola Superior do Ministério Público do Distrito Federal e Territórios, 2015, p. 21-51.

. The myth of punitiveness. Theoretical Criminology, vol. 11, n. 2, 2007, p. 261- 281.

Um guia realista para a reforma penal na América Latina. Trad. António Pedro Dores. Disponível em: http://www.criminologiacritica.com.br/arquivos/1312053453.pdf Acesso em 30 de julho de 2011.

PRANDO, Camila Cardoso de Mello. Representações e corpos no saber criminológico: por quem falamos, com quem falamos? Palestra ministrada no I Congresso de Criminologia(s): crítica(s), minimalismo(s) e abolicionismo(s). João Pessoa, 2015. Texto gentilmente cedido pela autora.

SANTOS, Juarez Cirino dos. A Criminologia da repressão. Rio de Janeiro: Forense, 1979. A Criminologia Radical. Rio de Janeiro: Forense, 1981.

SHANK, Gregory. Looking back: radical criminology and social movements. Social Justice. San Francisco, 1999. Disponível em: http://www.historyisaweapon.com/defcon1/shankcrimin.html Acesso em 28 de junho de 2013. 
SWAANINGEN, René van. Reclaiming critical criminology: social justice and the European tradition. Theoretical Criminology. London, 1999, p. 5-28. DOI 101177/1362480699003001001

TAYLOR, Ian; WALTON, Paulo; YOUNG, Jock. Criminologia crítica. Trad. Juarez Cirino dos Santos e Sergio Tancredo. Rio de Janeiro: Edições Graal, 1980.

ZAFFARONI, Eugenio Raúl. Em busca das penas perdidas: a perda de legitimidade do sistema penal. 5 ed. Trad. Vânia Romano e Amir Lopes da Conceição. Rio de Janeiro: Revan, 2001a.

La ingeniería institucional criminal: sobre la necesaria interdisciplinaridad constructiva entre derecho penal y politología. Revista Brasileira de Ciências Criminais. São Paulo, 2000, n. 29, p. 247-254.

. La palabra de los muertos. Buenos Aires: Ediar, 2012 